\title{
Experimental and Analytical Modal Analysis of a Crankshaft
}

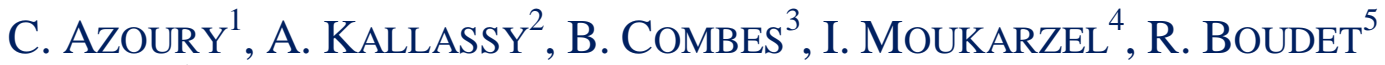 \\ ${ }^{I}$ MECHANICAL ENGINEERING DEPARTMENT, LEBANESE UNIVERSITY, LEBANON \\ ${ }^{2}$ MECHANICAL ENGINEERING DEPARTMENT, LEBANESE UNIVERSITY, LEBANON \\ ${ }^{3}$ MECHANICAL ENGINEERING LAB, PAUL-SABATIER UNIVERSITY, TOULOUSE (LGMT), FRANCE \\ ${ }^{4}$ MECHANICAL ENGINEERING DEPARTMENT, LEBANESE UNIVERSITY, LEBANON \\ ${ }^{5}$ MECHANICAL ENGINEERING LAB, PAUL-SABATIER UNIVERSITY, TOULOUSE (LGMT), FRANCE
}

\begin{abstract}
The paper presents the experimental and analytical modal analysis of a crankshaft. The effective material and geometrical properties are measured, and the dynamic behavior is investigated through impact testing. The three-dimensional finite element models are constructed and an analytical modal analysis is thenperformed to generate natural frequencies and mode shapes in the three-orthogonal directions. The finite element modelagrees well with the experimental tests and can serve as a baseline model of the crankshaft.
\end{abstract}

Keywords:Experimental modal analysis (EMA), finite element analysis (FEA),FFT (Fast Fourier Transformation), crankshaft.

\section{Introduction}

The experimental modal analysis (EMA) means the extractionof modal parameters (frequencies, damping ratios, andmode shapes) from measurements of dynamic responses (Rao, 2004).Basically, it is carriedout according to both input and output measurement data throughthe frequency response functions (FRFs) in the frequency domain,or impulse response functions (IRFs) in the time domain. For mechanical engineering structures, the dynamic responses (output) are thedirect records of the sensors that are installed at several locations (Ren, 2004).

The finite element analysis (FEA) is currently a common way toperform an analytical modal analysis of crankshafts. However,some problems always occur when establishing an accurateFE model of the existing structure. The problem arises not onlyfrom the errors resulting from simplified assumptions made inmodeling of the complicated structures but also from parametererrors due to structural damage and uncertainties in the materialand geometric properties (Ren, 2004).

The FEA is analytical, the EMA is experimental and modes are the common ground between the two. In fact the EMA is still used to validate FEA models, but it is also heavily used for troubleshooting noise and vibration problems in the field. Once an FEA model has been validated, it can be used for a variety of static and dynamic load simulations.

This paper concentrates on both experimental and analyticalmodal analysis of a crankshaft. Analytical work involved the development of a three-dimensional FE model.A modal analysis was performed to provide frequenciesand mode shapes. Results of the FE modal analysis werecompared with those obtained from the EMA.

\section{Crankshaft Description}

The crankshaft is that of a Peugeot 80 's model (Fig. 1). It is made of cast iron.

To construct the geometry of the crankshaft and in order to have precise measurements, we have used the three-dimensional metrology (Fig.2)

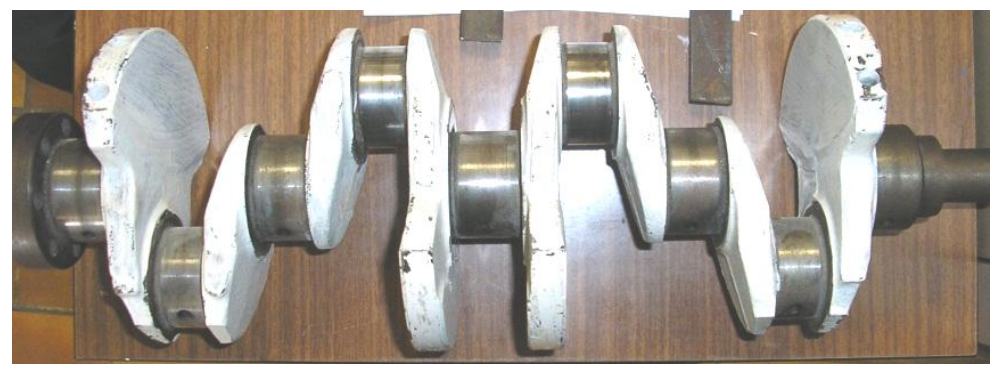

Fig. 1.Facade view showing the crankshaft 
IOSR Journal of Engineering

Apr. 2012, Vol. 2(4) pp: 674-684

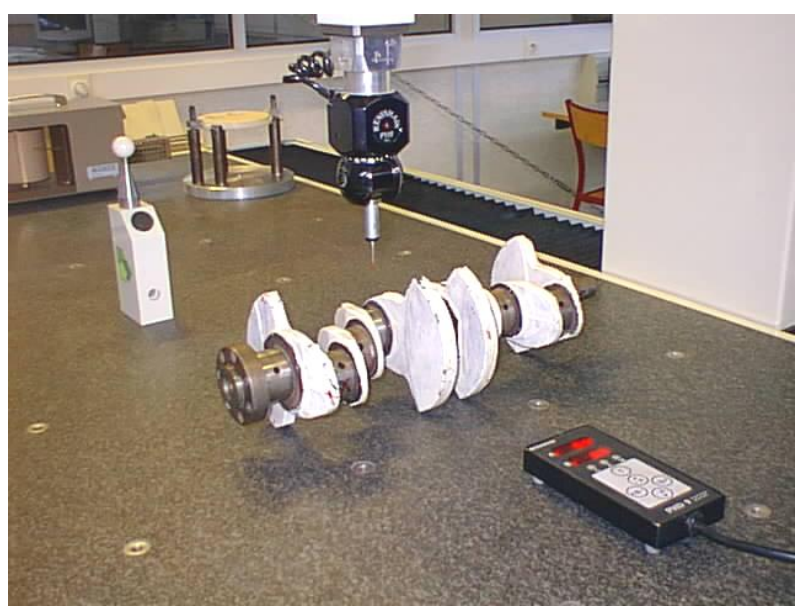

Fig.2. Crankshaft on the three-dimensional metrology device

Fig.3shows the dimensions of the crankshaft from the measurements done using the three-dimensionalmetrology device.

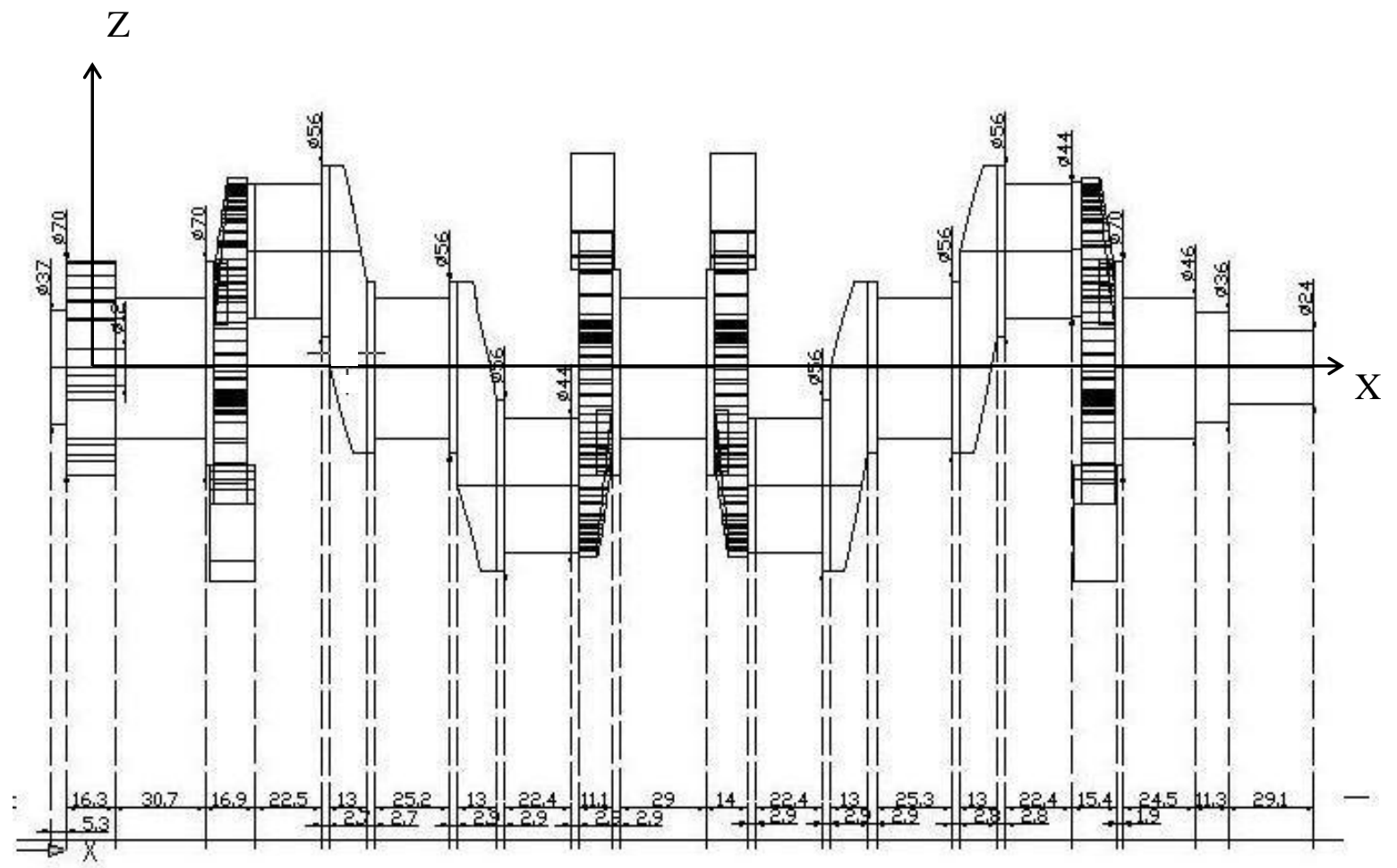

Fig. 3. Dimensions of the crankshaft (mm) 
IOSR Journal of Engineering

Apr. 2012, Vol. 2(4) pp: 674-684

To measure the Young's modulus of the material of the crankshaft, the ultrasonic method was used (Fig. 4).

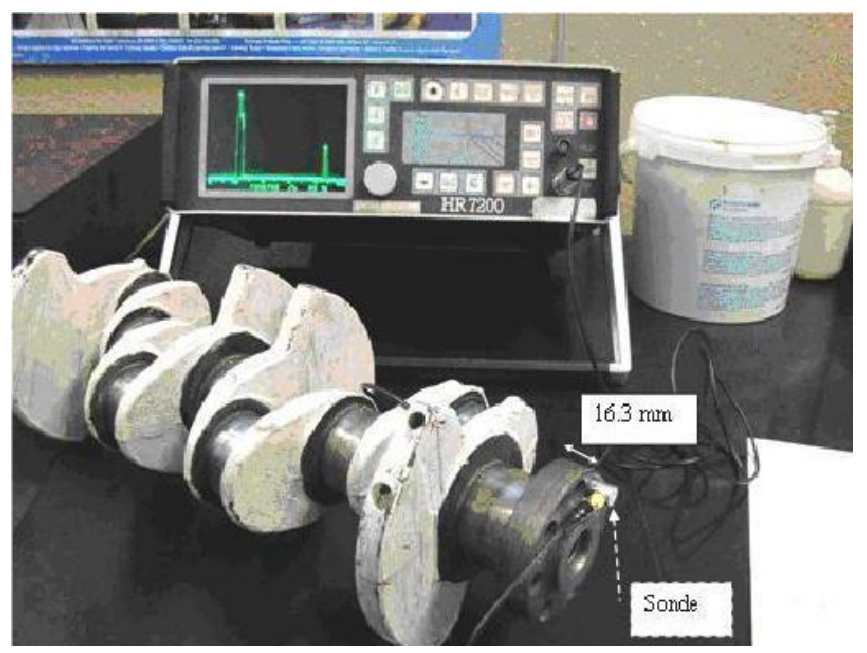

Fig. 4. Crankshaft and the ultrasonic device

A sonic wave is emitted in the material of the crankshaft and it took $5.7710^{-6}$ seconds for the wave to traverse $32.6 \mathrm{~mm}(2 \times 16.3 \mathrm{~mm}$; back and forth).

Knowing that the velocity equals the distance divided by the time, it was found that the velocity of propagation of the sonic wave is $5719 \mathrm{~m} / \mathrm{s}$. Using this number, giventhat the material is isotropic and homogenous we have:

$\mathrm{V}_{\mathrm{OL}}=\sqrt{\frac{1-v}{(1+v)(1-2 v)} \frac{E}{\rho}}$

Then $E=\frac{(1+v)(1-2 v) \rho V_{O L}^{2}}{1-v}$

Where $v=$ Poisson coefficient $=0.31, \mathrm{E}=$ Young's Modulus; value to be found, $\rho=$ density $=7800 \mathrm{Kg} / \mathrm{m}^{3}$,

$\mathrm{V}_{\mathrm{OL}}=$ velocity of the longitudinal wave $=5719 \mathrm{~m} / \mathrm{s}$.

We can find $\mathrm{E}=184.05 \mathrm{GPa}$.

\section{Finite Element Modeling}

Now that the geometrical and mechanical properties of the crankshaft are found, we can proceed with the finite element modeling. Three-dimensional linear elastic finite element model has been constructed using Visual Nastran $4 \mathrm{D}^{\circledR}$ FEA software.The crankshaft is modeled using solid ten-nodedtetrahedral elements (each node has 3 degrees of freedom UX,UY and UZ).(Fig. 5)

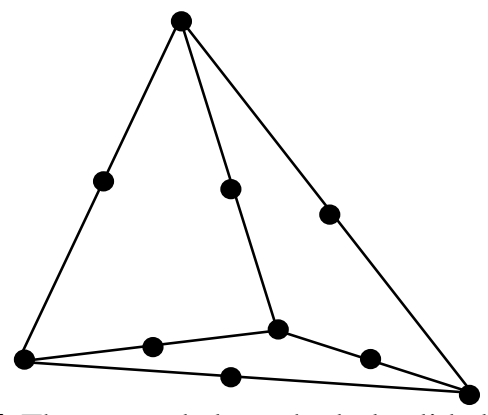

Fig. 5. The ten-noded tetrahedral solid element 
IOSR Journal of Engineering

Apr. 2012, Vol. 2(4) pp: 674-684

Fig. 6 shows the full three-dimensional (3D) view of the finite element model of the crankshaft:

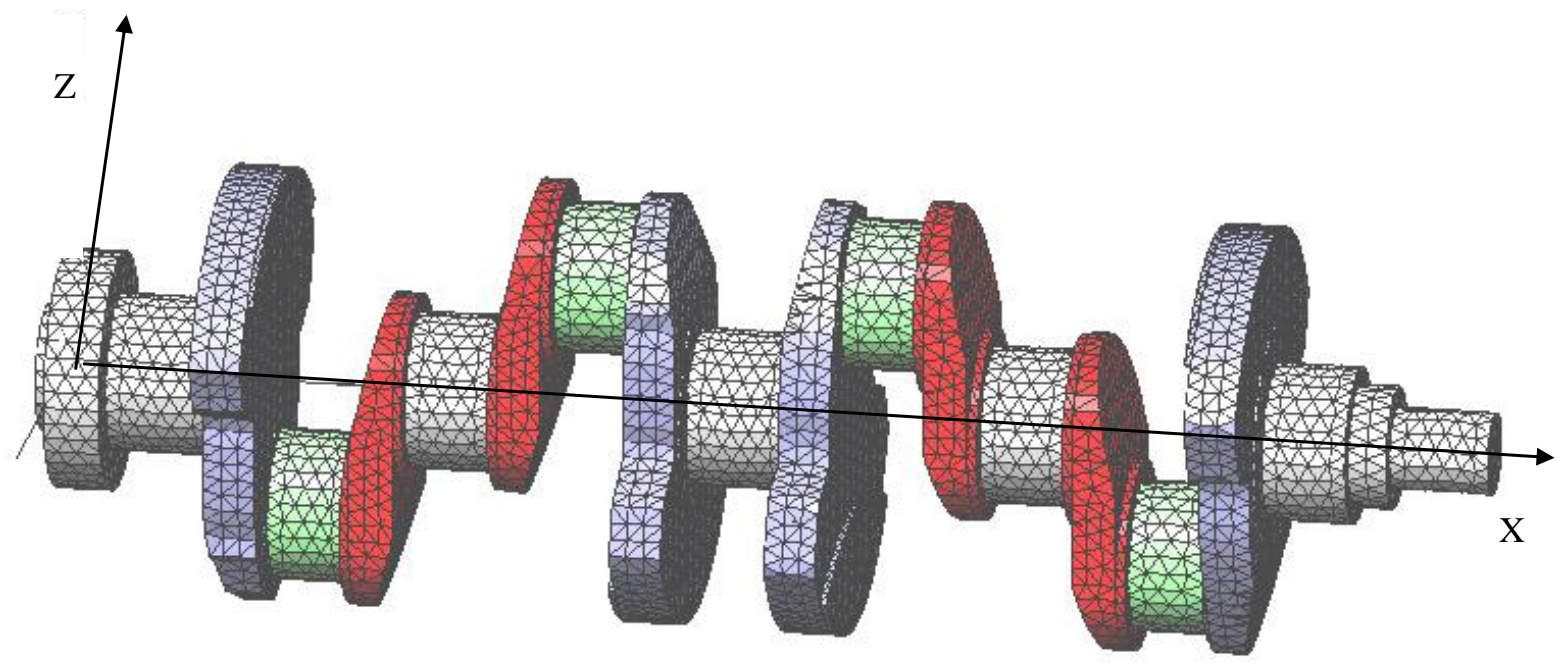

Fig. 6. The finite element model of the crankshaft

The full model has a total of 67,657 tetrahedral solid elements with more than 120,000 nodes. The unit mesh size is $5 \mathrm{~mm}$.

The crankshaft is analyzed in free-free position, so rigid body modes are expected in the results. With 6 modes to extract, the results of the modal analysis are shown in Table 1.

Table.1 Calculated frequencies from the FEA

\begin{tabular}{ccc}
\hline Mode & $\begin{array}{c}\text { Frequencies } \\
\text { FEA (Hz) }\end{array}$ & $\begin{array}{c}\text { Description } \\
\text { of the mode }\end{array}$ \\
\hline 1 & 367.7 & $\begin{array}{c}\text { First vertical deflection } \\
\text { (Bending in xz plane) }\end{array}$ \\
\hline 2 & 496.1 & $\begin{array}{c}\text { First horizontal deflection } \\
\text { (Bending in xy plane) }\end{array}$ \\
\hline 3 & 859.2 & $\begin{array}{c}\text { Second vertical deflection } \\
\text { (Bending in xz plane) }\end{array}$ \\
\hline 5 & 972.6 & $\begin{array}{c}\text { First Longitudinal } \\
\text { (along x axis) }\end{array}$ \\
\hline 6 & 1284.0 & $\begin{array}{c}\text { First twisting mode } \\
\text { (around x axis) }\end{array}$ \\
\hline
\end{tabular}

The mode shapes of the crankshaft are shownin Fig. 7 sorted from the lowest frequency to the highest:

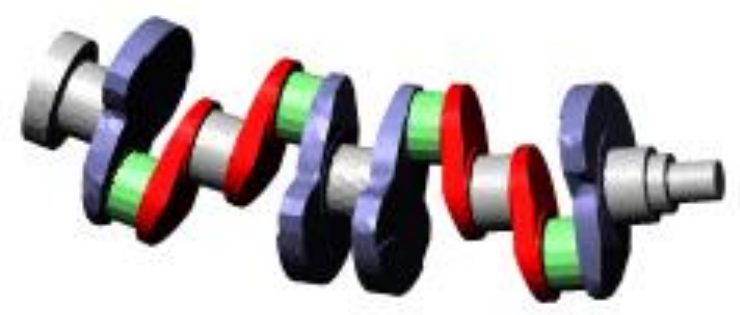

(a) $f_{1}=367.7 \mathrm{~Hz}$ 


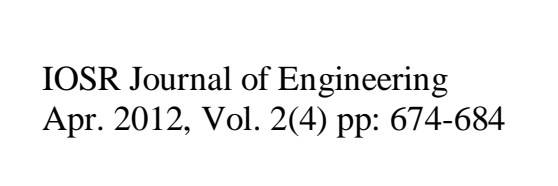

8

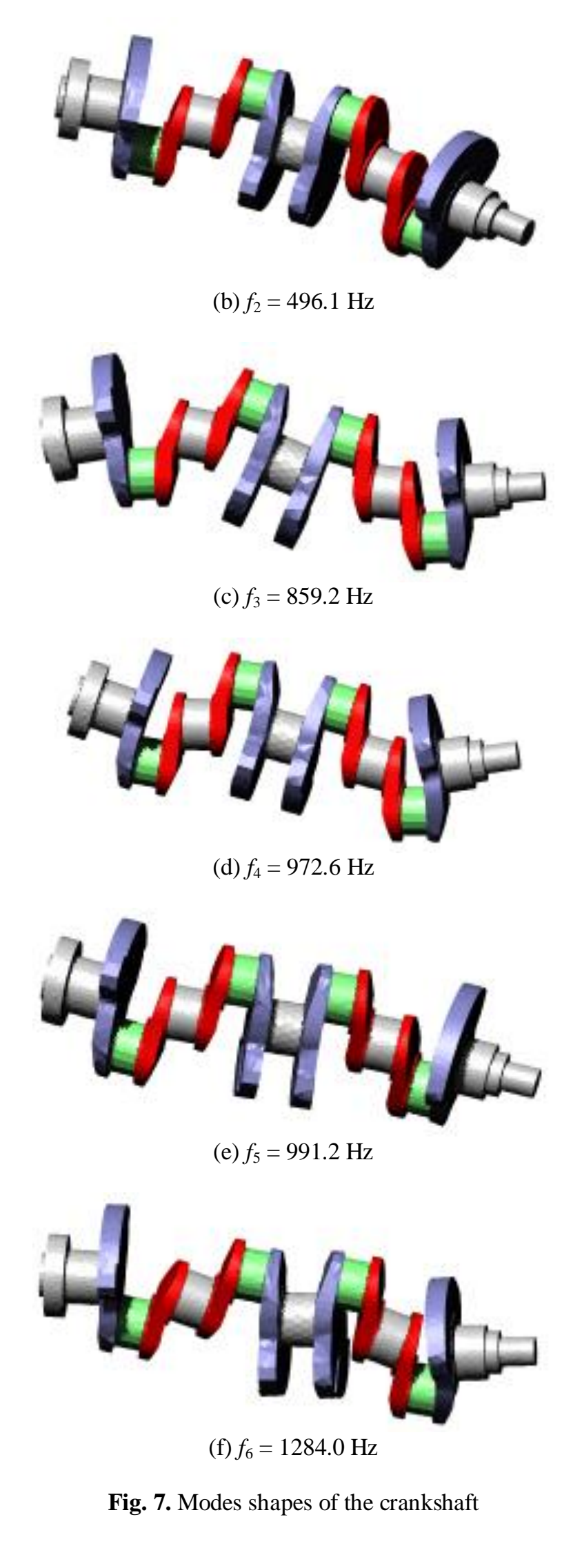


IOSR Journal of Engineering

Apr. 2012, Vol. 2(4) pp: 674-684

\section{Experimental Modal Analysis (EMA)}

EMA has grown steadily in popularity since the advent of the digital FFT (Fast Fourier Transformation) spectrum analyzer in the early 1970's (Schwarz \& Richardson).

In this paper, we will make FRF measurements with a FFT analyzer, modal excitation techniques, and modal parameter estimation from a set of FRFs (curve fitting).

Experimental modal parameters (frequency, damping, and mode shape) are also obtained from a set of FRF measurements.

The FRF describes the input-output relationship between two points on a structure as a function of frequency. Since both force and motion are vector quantities, they have directions associated with them. Therefore, anFRF is actually defined between a single input DOF (point \&direction), and a single output DOF.

FRF is defined as theratio ofthe Fourier transform of an output response $(\mathrm{X}(\omega))$ dividedby the Fourier transform of the input force $(F(\omega))$ that caused the output (See Fig. 8).

An FRF is a complexed valued function of frequency. Actually FRF measurements are computed in a FFT analyzer.

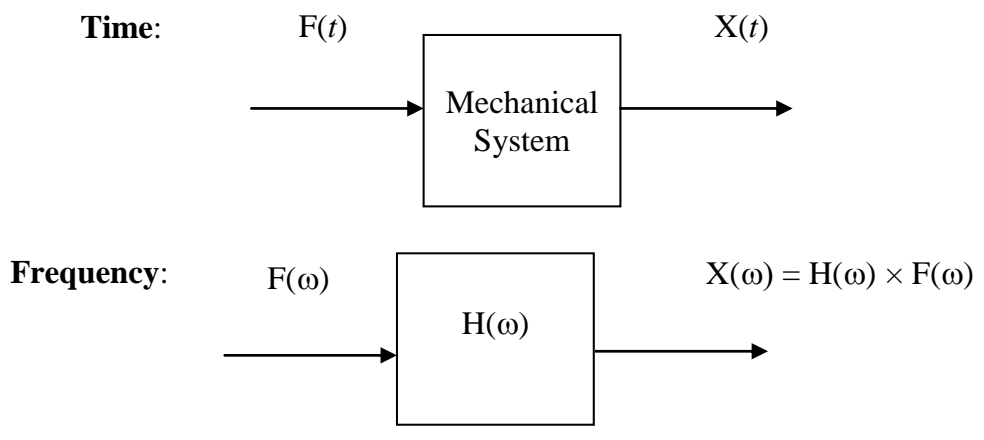

Fig. 8.Time and Frequency Domain

\section{Exciting Modes with Impact Testing}

Impact testing is a fast, convenient, andlow cost way of finding the modes of machines and structures.

All the tests were performed at the University of PAUL SABATIER, Toulouse, in the Mechanical engineering LAB, at LGMT - CRITT.

The following equipmentis required to perform an impact test:

1. An impact hammer with a load cell attached to its headto measure the input force (Fig. 9).

2. An accelerometer to measure the response accelerationat a fixed point \& direction (Fig. 9).

3. A 2 channel FFT analyzer to compute FRFs.

4. Post-processing modal software for identifying modalparameters and displaying the mode shapes in animation.

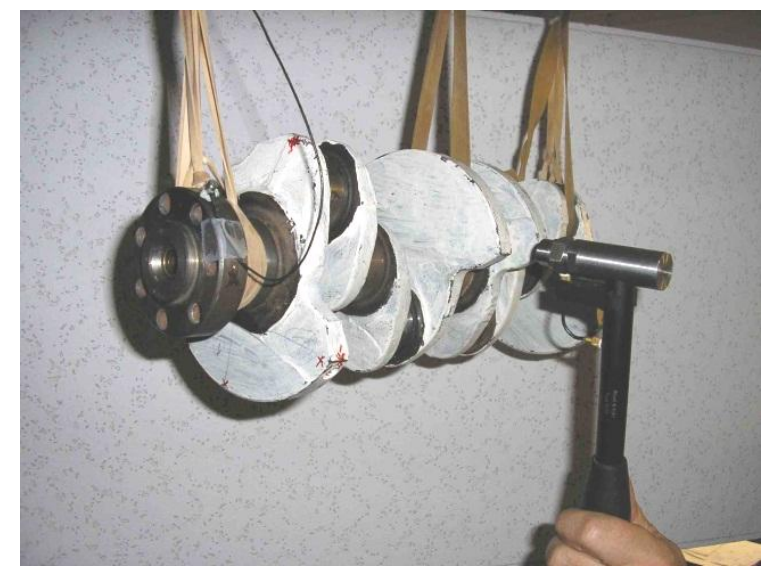

Fig. 9. The accelerometer to the left,the impact hammer to the right 
IOSR Journal of Engineering

Apr. 2012, Vol. 2(4) pp: 674-684

The whole process of the impact testing is depicted in Fig. 10.

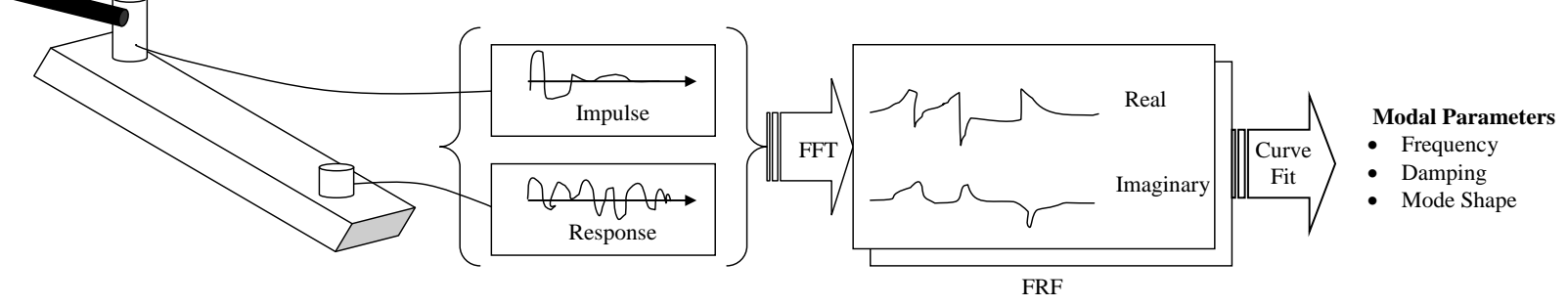

Fig. 10. The process of the impact testing

In general a wide variety of structures and machines can be impacttested. Of course, different sized hammers are required toprovide the appropriate impact force, depending on the sizeof the structure; small hammers for small structures, largehammers for large structures.

\section{6. $\quad$ Roving Hammer Test}

A roving hammer test is the most common type of impact test. In this test, the accelerometer is fixed at a single DOF, and the structure is impacted at as many DOFs as desired to define the mode shapes of the structure. Using a 2-channel FFT analyzer, FRFs are computed one at a time, between each impact DOF and the fixed response DOF.

\section{Testing the reliability of the EMA}

Before applying the EMA, its reliability was tested on four steel bars, two of them with circular section and the other ones with rectangular section. For such simple bars the natural frequencies are known analytically.

Again the bars are suspended on elastic cables as if they are in free-free position.

The analytical formula of the frequency of the lateralvibration for a free-free beam is given by:

$f(\mathrm{~Hz})=\frac{\lambda^{2}}{2 \pi L^{2}} \sqrt{\frac{E I}{\rho A}}$

Where: $\mathrm{E}=$ Young's Modulus; $\mathrm{I}=$ inertia of the bar, $\rho=$ density $=7800 \mathrm{Kg} / \mathrm{m}^{3}, \mathrm{~A}=$ cross-sectional areaof the bar, $\mathrm{L}=$ length of the bar and the values of $\lambda$ are given in Table. 2 .

Table. 2. Values of $\lambda$ (free-free beam "lateral vibration")

\begin{tabular}{cc}
\hline Mode number & $\lambda$ \\
\hline 1 & 4.730 \\
\hline 2 & 7.853 \\
\hline 3 & 10.995 \\
\hline 4 & 14.137 \\
\hline 5 & 17.278 \\
\hline 6 & 20.420 \\
\hline. &. \\
\hline. &. \\
\hline. &. \\
\hline
\end{tabular}

When comparing the frequencies of the EMA to the frequencies of the analytical solution, we have found an average difference of $1.5 \%$ (See Appendix Table. 5).

Now that the theoretical values are close to the experimental ones, hence the EMA is quite reliable, thus we can move for the experimenton the crankshaft.

In this experiment, the crankshaft is suspended on elastic cables (Fig. 11), so that rigid body modes have very small frequencies compared to those of the deformation modes. 
IOSR Journal of Engineering Apr. 2012, Vol. 2(4) pp: 674-684

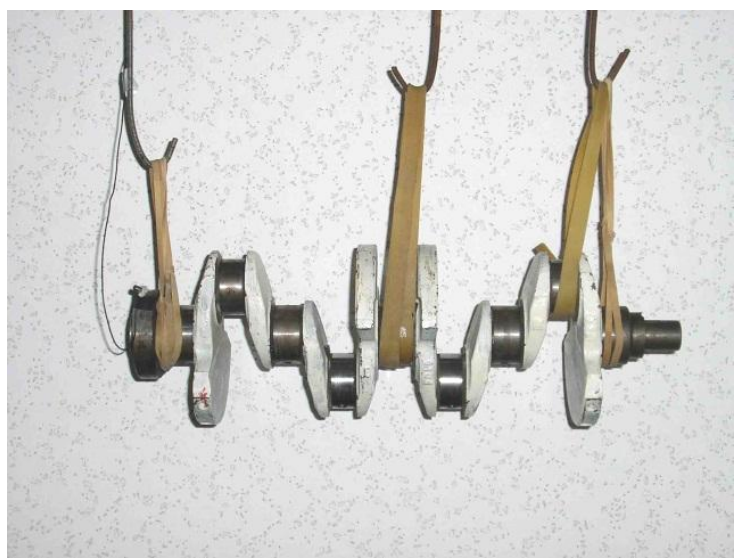

Fig.11. Crankshaft suspended on elastic cables

Fixing the accelerometer at a single DOF, the crankshaft was impacted at many DOF to excite all modes (see Appendix. Fig. 13for the position and directions of all DOF, and Appendix. Table. 6 for the coordinates of all points). After every impact the measurements were taken and saved. The software used is LMS ${ }^{\circledR}$ (Leuven Measurement System).

From the measured FRFs, the software evaluates natural frequencies and mode shapes as well as damping ratios, but the latter are not shown. Table. 3. lists the identified frequencies from the EMA using LMS software.

Table. 3 Calculated frequencies from the EMA

\begin{tabular}{cc}
\hline Mode & Frequencies EMA $(\mathrm{Hz})$ \\
\hline 1 & 350.7 \\
\hline 2 & 481.8 \\
\hline 3 & 799.6 \\
\hline 4 & 874.5 \\
\hline 5 & 965.3 \\
\hline 6 & 1127.8 \\
\hline
\end{tabular}

Animation of different modes is also available (see Fig. 12)

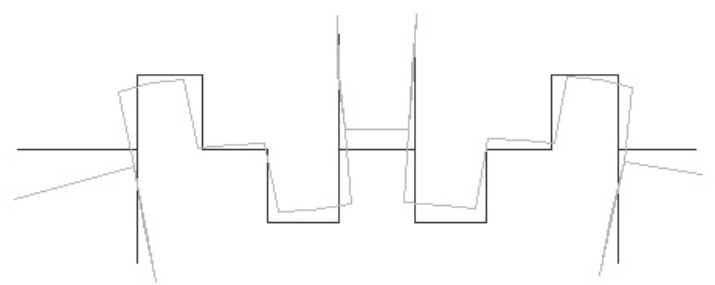

Fig. 12. First mode of vibration using LMS software

\section{Results and Comparison}

The FE analytical modal analysis was validated by EMA in terms of natural frequencies and mode shapes. Theoretically, a perfect model would match all experimentally determined mode shapes and frequencies exactly. In practice, it is not expected to be a perfect match between all analytical and measured modal properties. Therefore, only the most structurally significant modes and frequencies are used in the comparison process. 
IOSR Journal of Engineering

Apr. 2012, Vol. 2(4) pp: 674-684

Table.4.summarizes the frequencies of both methods, EMA and FEA. $\Delta$ is the relative difference between the frequencies of both methods for the given mode.

Table. 4. Frequencies (Hz) from both methods (EMA and FEA)

\begin{tabular}{cccc}
\hline Mode & $\begin{array}{c}\text { Frequencies } \\
\text { EMA (Hz) }\end{array}$ & $\begin{array}{c}\text { Frequencies } \\
\text { FEA (Hz) }\end{array}$ & $\boldsymbol{\Delta}$ \\
\hline 1 & 350.7 & 367.7 & $4.62 \%$ \\
2 & 481.8 & 496.1 & $2.88 \%$ \\
3 & 799.6 & 859.2 & $6.94 \%$ \\
4 & 874.5 & 972.6 & $10.09 \%$ \\
5 & 965.3 & 991.2 & $2.61 \%$ \\
6 & 1127.8 & 1284.0 & $12.17 \%$ \\
\hline
\end{tabular}

\section{Conclusions}

The analytical modal analysis with 3D finite element models of the crankshaft is compared with the EMA. The results from finite element model agree well with the experimental values. This model is suitable for the dynamic analysis of the crankshaft. The validated finite element model can be used for further dynamic analysis and evaluation of structural performance from loadings.

\section{Appendix}

In this appendix:

- Table. 5 lists the frequencies $(\mathrm{Hz})$ of the four barsfrom both methods the experimental and the analytical.

- Fig. 13. shows the impact points (1 to $37 \mathrm{DOF}$ ) on the crankshaft

- Fig. 14. shows a 3D view of the position of the impacted points

- Table. 6. lists the coordinates of all impacted points on the crankshaft. $\mathrm{O}(0,0,0)$ is the origin of the axes, A $(12,12,121)$ is where the accelerometer is attached, point 1 to point 21 are the impacted points and point 22 to point 37 are complementary points used for the visualization of the deformed shapes.

Table. 5. Analytical and Experimental frequencies $(\mathrm{Hz})$ of the four test bars

Numbers are frequencies in $\mathrm{Hz}$

\begin{tabular}{|c|c|c|c|c|c|c|c|c|c|c|c|c|}
\hline \multirow[b]{2}{*}{ Mode } & \multicolumn{3}{|c|}{$\begin{array}{c}\text { Circular Section } \\
\mathrm{L}=\mathbf{2 0 0} \mathrm{mm}\end{array}$} & \multicolumn{3}{|c|}{$\begin{array}{c}\text { Circular Section } \\
\mathrm{L}=1000 \mathrm{~mm}\end{array}$} & \multicolumn{3}{|c|}{$\begin{array}{c}\text { Rectangular Section } \\
\mathrm{L}=\mathbf{2 0 0} \mathrm{mm}\end{array}$} & \multicolumn{3}{|c|}{$\begin{array}{c}\text { Rectangular Section } \\
\mathbf{L}=1000 \mathrm{~mm}\end{array}$} \\
\hline & Ana & EMA & $\Delta$ & Ana & EMA & $\Delta$ & Ana & EMA & $\Delta$ & Ana & EMA & $\Delta$ \\
\hline 1 & 1708 & 1790 & $4.6 \%$ & 68 & 69 & $1.4 \%$ & 1315 & 1347 & $2.4 \%$ & 53 & 53 & $0.8 \%$ \\
\hline 2 & 4750 & 4960 & $4.2 \%$ & 190 & 192 & $1.0 \%$ & 2630 & 2601 & $-1.1 \%$ & 105 & 107 & $1.7 \%$ \\
\hline 3 & 9336 & 9595 & $2.7 \%$ & 373 & 376 & $0.8 \%$ & 3658 & 3618 & $-1.1 \%$ & 146 & 148 & $1.1 \%$ \\
\hline 4 & & & & 615 & 621 & $1.0 \%$ & 7189 & 7010 & $-2.6 \%$ & 288 & 286 & $-0.5 \%$ \\
\hline 5 & & & & & & & 7316 & 7210 & $-1.5 \%$ & 293 & 294 & $0.5 \%$ \\
\hline 6 & & & & & & & 11846 & 11606 & $-2.1 \%$ & 474 & 473 & $-0.2 \%$ \\
\hline 7 & & & & & & & & & & 575 & 572 & $-0.5 \%$ \\
\hline 8 & & & & & & & & & & 948 & 941 & $-0.7 \%$ \\
\hline
\end{tabular}

- Ana = Analytical, i.e. from the formula of natural frequency (transverse vibration) of a beam in free-free position.

- $\Delta$ is the relative difference between the frequencies of both methods for the given mode 
IOSR Journal of Engineering

Apr. 2012, Vol. 2(4) pp: 674-684

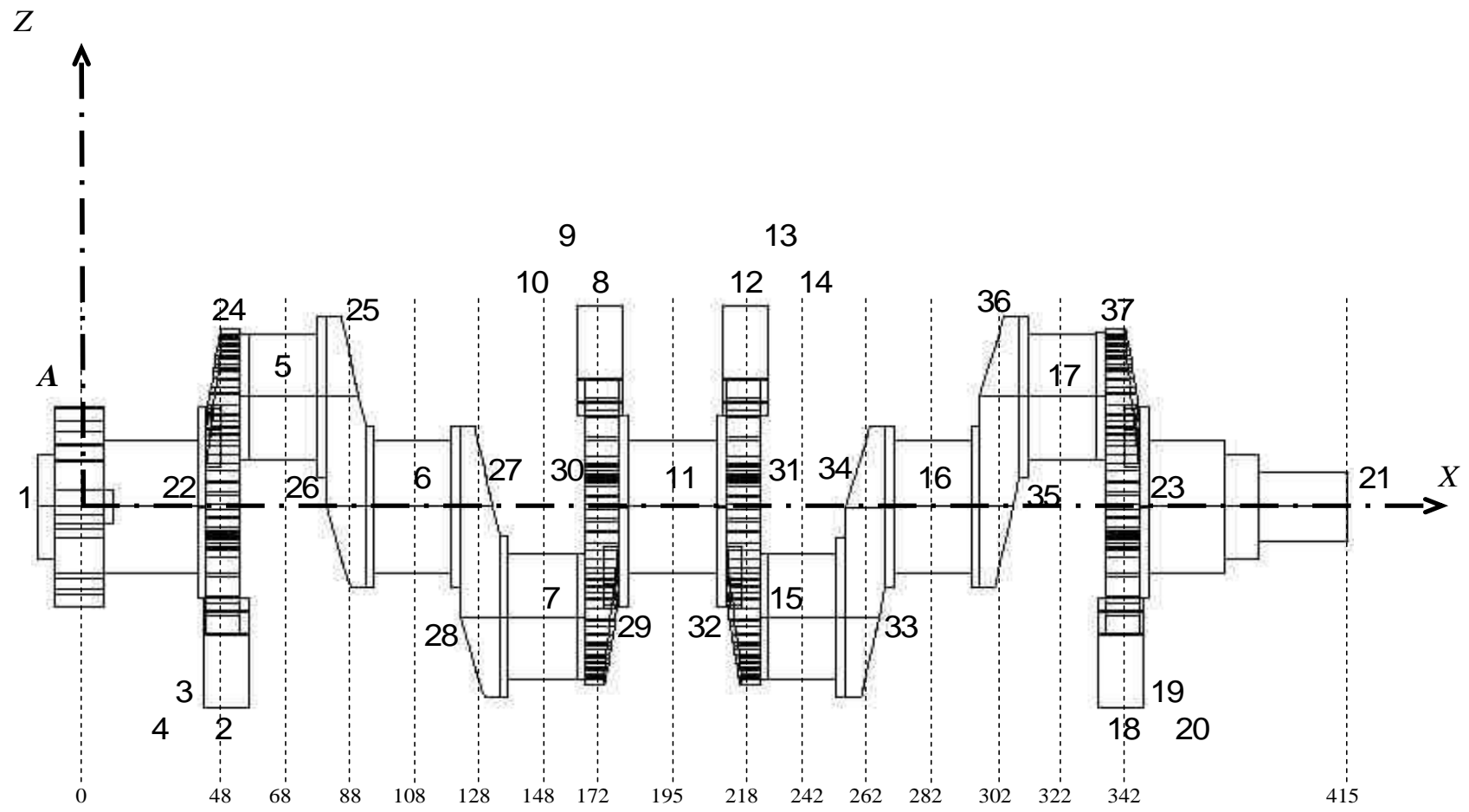

Fig. 13. Impact points (1 to $37 \mathrm{DOF}$ ) on the crankshaft

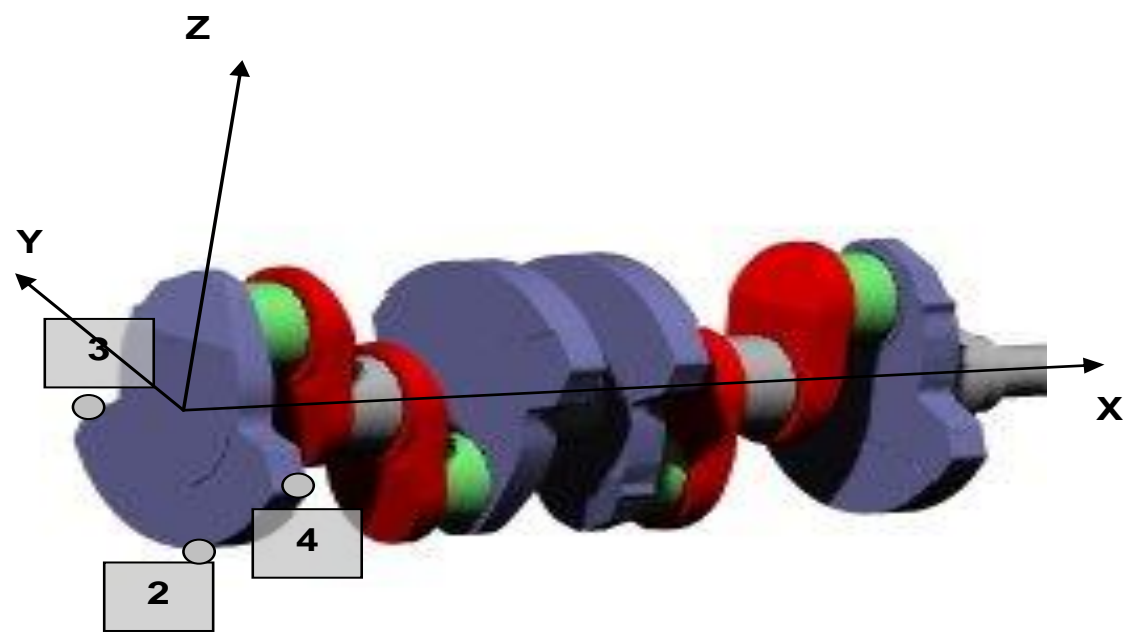

Fig. 14. A 3 D view of the position of some impacted points (here only points 2,3 and 4 are shown)

Table. 6. Coordinates of all impacted points on the crankshaft

\begin{tabular}{|ccccc|}
\hline Node Number & $\mathbf{X}(\mathbf{m m})$ & $\mathbf{Y}(\mathbf{m m})$ & $\mathbf{Z}(\mathbf{m m})$ & $\begin{array}{c}\text { Impact } \\
\text { Direction }\end{array}$ \\
\hline 1 & 0 & 0 & 0 & $\mathrm{X}, \mathrm{Y}, \mathrm{Z}$ \\
\hline 2 & 48 & 0 & -70 & $\mathrm{X}, \mathrm{Z}$ \\
\hline 3 & 48 & 70 & -35 & $\mathrm{X}, \mathrm{Y}$ \\
\hline
\end{tabular}


IOSR Journal of Engineering Apr. 2012, Vol. 2(4) pp: 674-684

\begin{tabular}{|c|c|c|c|c|}
\hline 4 & 48 & -70 & -35 & $\mathrm{X}$ \\
\hline 5 & 68 & 0 & 45 & $\mathrm{X}, \mathrm{Y}, \mathrm{Z}$ \\
\hline 6 & 108 & 0 & 0 & $\mathrm{Y}, \mathrm{Z}$ \\
\hline 7 & 148 & 0 & -45 & $\mathrm{X}, \mathrm{Y}, \mathrm{Z}$ \\
\hline 8 & 172 & 0 & 70 & $\mathrm{X}, \mathrm{Z}$ \\
\hline 9 & 172 & 70 & 35 & $\mathrm{X}, \mathrm{Y}$ \\
\hline 10 & 172 & -70 & 35 & $\mathrm{X}, \mathrm{Y}$ \\
\hline 11 & 195 & 0 & 0 & $\mathrm{Y}, \mathrm{Z}$ \\
\hline 12 & 218 & 0 & 70 & $\mathrm{X}, \mathrm{Z}$ \\
\hline 13 & 218 & 70 & 35 & $\mathrm{X}, \mathrm{Y}$ \\
\hline 14 & 218 & -70 & 35 & $\mathrm{X}, \mathrm{Y}$ \\
\hline 15 & 242 & 0 & -45 & $\mathrm{X}, \mathrm{Y}, \mathrm{Z}$ \\
\hline 16 & 282 & 0 & 0 & $\mathrm{Y}, \mathrm{Z}$ \\
\hline 17 & 322 & 0 & 45 & $\mathrm{X}, \mathrm{Y}, \mathrm{Z}$ \\
\hline 18 & 342 & 0 & -70 & $\mathrm{X}, \mathrm{Z}$ \\
\hline 19 & 342 & 70 & -35 & $\mathrm{X}, \mathrm{Y}$ \\
\hline 20 & 342 & -70 & -35 & $\mathrm{X}, \mathrm{Y}$ \\
\hline 21 & 415 & 0 & 0 & $\mathrm{X}, \mathrm{Y}$ \\
\hline 22 & 48 & 0 & 0 & $*$ \\
\hline 23 & 342 & 0 & 0 & $*$ \\
\hline 24 & 48 & 0 & 45 & $*$ \\
\hline 25 & 88 & 0 & 45 & $*$ \\
\hline 26 & 88 & 0 & 0 & $*$ \\
\hline 27 & 128 & 0 & 0 & $*$ \\
\hline 28 & 128 & 0 & -45 & $*$ \\
\hline 29 & 172 & 0 & -45 & $*$ \\
\hline 30 & 172 & 0 & 0 & $*$ \\
\hline 31 & 218 & 0 & 0 & $*$ \\
\hline 32 & 218 & 0 & -45 & $*$ \\
\hline 33 & 262 & 0 & -45 & $*$ \\
\hline 34 & 262 & 0 & 0 & $*$ \\
\hline 35 & 302 & 0 & 0 & $*$ \\
\hline 36 & 302 & 0 & 45 & $*$ \\
\hline 37 & 342 & 0 & 45 & $*$ \\
\hline
\end{tabular}

* The corresponding direction (DOF) is interpolated from adjacent directions

\section{References}

1. Ewins, D. J. (2000). Modal testing: Theory and practice, Research Studies Press Ltd., Hertfordshire, U.K.

2. Maia, N. M. M., and Silva, J. M. M., eds. (1997). Theoretical and experimental modal analysis, Research Studies Press Ltd., Hertfordshire, U.K.

3. Ramirez, R. W. (1985). The FFT: Fundamentals and Concepts, Prentice Hall.

4. Rao. (2004). Mechanical Vibrations, $4^{\text {th }}$ Edition.

5. Ren, Wei-Xin (2004). Experimental and Analytical Modal Analysis of Steel Arch Bridge. Journal of structural Engineering ASCE

6. Richardson, M (2005). Modal Analysis versus Finite - Element Analysis

7. Schwarz, B \& Richardson M, Experimental Modal Analysis, CSI reliability week, Orlando, (1999) 